\title{
Fradiamine $A$, a new siderophore from the deep-sea actinomycete Streptomyces fradiae MM456M-mF7
}

\author{
Yasuhiro Takehana ${ }^{1}$, Maya Umekita $^{1}$, Masaki Hatano ${ }^{1}$, Chiaki Kato ${ }^{2}$, Ryuichi Sawa ${ }^{1}$ and Masayuki Igarashi ${ }^{1}$ \\ New bioactive substances were identified from several marine actinomycetes strains by LC-HRESI-MS based non-targeted \\ metabolomics. A new siderophore and its derivative, named fradiamines A and B, were isolated from the extract of the deep-sea \\ actinomycetes Streptomyces fradiae MM456M-mF7 by Diaion CHP-20P, Sephadex LH-20 column chromatography and HPLC. \\ Fradiamine A was a new compound, but fradiamine B was previously patented as a sweetness enhancer. Their structures were \\ determined by NMR and LC-HRESI-MS/MS analysis. Fradiamines A and B contained two alkyl amines asymmetrically bonded to \\ citrate, a type of structure derived from actinomycetes and other bacteria and rarely observed in siderophores. Fradiamines $A$ and \\ B showed moderate antibiotic activity against Clostridium difficile with $\mathrm{IC}_{50}$ values of 32 and $8 \mu \mathrm{g} \mathrm{ml}{ }^{-1}$, respectively.
} The Journal of Antibiotics (2017) 70, 611-615; doi:10.1038/ja.2017.26; published online 1 March 2017

\section{INTRODUCTION}

The secondary metabolites of terrestrial actinomycetes are major sources of novel bioactive compounds. ${ }^{1,2}$ Recently, discovering efficiency of the medically useful antibiotics with novel structures has been decreased. ${ }^{3,4}$ The deep-sea provides unique environmental factors different from those of the terrestrial environment, such as temperature, aeration and nutrition availability. These factors all affect the expression of secondary metabolite genes. ${ }^{5,6}$ Numerous novel bioactive compounds were isolated from marine organisms. ${ }^{7}$ Marine actinomycetes also produced novel useful compounds, including the anticancer candidates salinosporamide A isolated from Salinispora tropica $^{8}$ and thiocoraline isolated from Micromonospora marina. ${ }^{9}$ Novel bioactive compounds are identified using biological activitybased screening methods. However, many bioactive compounds escape detection because suitable tests for measuring their biological activity are still missing. Physicochemical screening methods can also be used to detect novel bioactive compounds and avoid the limitations of bioactive assays. For example, the antimicrobial dienomycin isolated from Streptomyces sp., ${ }^{10}$ and the antifungal and protein kinase inhibitory substance staurosporine isolated from Streptomyces staurosporeus ${ }^{11}$ were discovered from the secondary metabolites of actinomycetes by color reaction-based physicochemical screening. In recent years, LC-HRESI-MS-based non-targeted metabolomics have been used in many laboratories. Several novel bioactive compounds were discovered using this method including photo-oxidative hemolysis inhibitors, trehangelins isolated from Polymorphospora rubra, ${ }^{12}$ and the antitrypanosomal substance mangromicin isolated from Lechevalieria aerocolonigenes. ${ }^{13}$ Therefore, we expected that novel compounds will be isolated from marine actinomycetes by physicochemical screening.

In this study, we screened secondary metabolites of various actinomycetes isolated from deep-sea sediment for novel bioactive compounds by LC-HRESI-MS analysis-based non-targeted metabolomics, a type of physicochemical screening. ${ }^{14,15}$ We identified two components not listed in the database from the extract of actinomycete strain MM456M-mF7 isolated from deep-sea sediment collected from the coast of Sagami Bay, Japan. The components were named fradiamines A (1) and B (2). Herein, we describe the isolation, structure determination and biological activities of fradiamines $\mathrm{A}$ and $\mathrm{B}$.

\section{RESULTS AND DISCUSSION}

Screening

Screening was performed based on LC-HRESI-MS analysis of the solvent extracts of fermentation materials, and extracted peaks from the MS data were identified using our in-house accurate masses database. The MS data analyses were performed using MS component extraction software to obtain accurate masses and the retention time index. These values were collated to our in-house accurate masses library (12 019 compounds). In the course of the screening, we found two components not listed in our library from actinomycete strain MM456M-mF7. The components were identified as protonated molecules of $m / z 435.2089$ (1) and 449.2243 (2).

Taxonomy of the strain MM456M-mF7

The strain MM456M-mF7 was isolated from sediment from the inside of Calyptogena community, Sagami Bay, Japan $\left(35^{\circ} 0.940^{\prime} \mathrm{N}\right.$

\footnotetext{
${ }^{1}$ Institute of Microbial Chemistry (BIKAKEN), Tokyo, Japan and ${ }^{2}$ Japan Agency for Marine-Earth Science and Technology (JAMSTEC), Kanagawa, Japan Correspondence: Dr R Sawa or Dr M Igarashi, Institute of Microbial Chemistry (BIKAKEN), Laboratory of Structural Chemistry and Biology or Microbiology, 3-14-23 Kamiosaki, Shinagawa-ku, Tokyo 141-0021, Japan.

E-mail: rsawa@bikaken.or.jp or igarashim@bikaken.or.jp

The authors dedicate this work to Professor Satoshi Ōmura, a distinguished Nobel Prize awardee in Physiology or Medicine 2015

Received 14 October 2016; revised 27 January 2017; accepted 30 January 2017; published online 1 March 2017
} 
<smiles>CC(=O)N(O)CCCCNC(=O)C(CC(=O)O)(CC(=O)NCCCN(O)C(C)=O)C(=O)O</smiles>

b<smiles>CC(=O)N(O)CCCCCNC(=O)C(O)(CC(=O)O)CC(=O)NCCCN(O)C(C)=O</smiles>

C

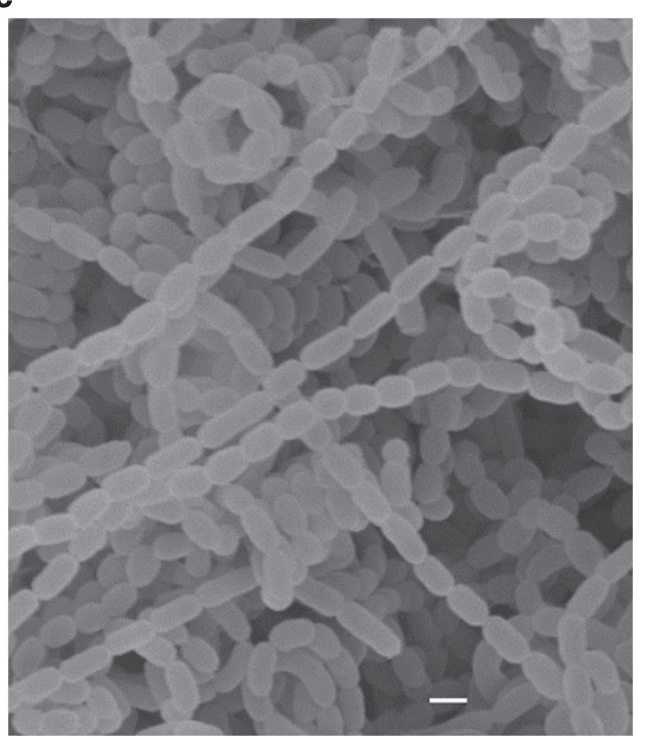

Figure 1 Structures of 1 (a) and 2 (b). (c) Scanning electron micrograph of strain MM456M-mF7 after growing on inorganic salt-starch agar (ISP medium no. 4) for 7 days at $30^{\circ} \mathrm{C}$. Scale bar, $1 \mu \mathrm{m}$.

$139^{\circ} 13.222^{\prime} \mathrm{E}$, depth: $\left.806 \mathrm{~m}\right)$. Strain MM456M-mF7 formed wellbranched substrate mycelia. This strain formed straight to flexuous aerial mycelia with imperfect or regular spirals of three to five turns (Figure 1c). Mature spore chains consisted of 11 to 30 or more spores. The spore was oval with a smooth surface and $0.6 \times 0.6-1.4 \times 0.5 \mu \mathrm{m}$ in size. The substrate mycelia were pale yellowish brown. The aerial mycelia were pinkish white to pink. These characteristics were observed on inorganic salt-starch agar (ISP medium no. 4). The type of diaminopimelic acid isomer in whole-cell hydrolysates of the strain MM456M-mF7 was the LL-form. The partial 16S ribosomal RNA gene sequence (1426 bp) was determined. The GenBank/EMBL/DDBJ accession number for the 16S rRNA gene sequence of MM456M-mF7 is LC120624. The strain showed high similarity with Streptomyces fradiae (NBRC $12773^{\mathrm{T}}, 1426 / 1426 \mathrm{bp}$, T: Type strain, 100\%). These phenotypic and genotypic data suggested that strain MM456M-mF7 belongs to $S$. fradiae. Therefore, the strain was designated as $S$. fradiae MM456M-mF7.

\section{Fermentation and isolation}

Fradiamines A (1) and B (2) were produced by solid-state culture. A total of $7 \mathrm{ml}$ of seed culture was transferred into a 500-ml K-1 flask containing $40 \mathrm{~g}$ of a producing medium. The fermentation was carried out at $30^{\circ} \mathrm{C}$ for 14 days in the dark.
Table 1 Physicochemical properties of compounds 1 and 2

\begin{tabular}{|c|c|c|}
\hline & 1 & 2 \\
\hline Appearance & Colorless syrup & Colorless syrup \\
\hline Optical rotation $[\alpha]_{D} 25$ & $+14.1^{\circ}($ c $0.39, \mathrm{MeOH})$ & $+15.8^{\circ}($ c $0.85, \mathrm{MeOH})$ \\
\hline UV $\lambda_{\max }^{\mathrm{H}_{2} \mathrm{O}}$ & End absorption & End absorption \\
\hline $\mathrm{IR}(\mathrm{KBr}) \nu_{\max } \mathrm{cm}^{-1}$ & $\begin{array}{c}3397,2938,2874,1715 \\
1637,1543,1420,1227\end{array}$ & $\begin{array}{c}3400,2938,2867,1716, \\
1633,1542,1419,1227\end{array}$ \\
\hline Molecular formula & $\mathrm{C}_{17} \mathrm{H}_{30} \mathrm{~N}_{4} \mathrm{O}_{9}$ & $\mathrm{C}_{18} \mathrm{H}_{32} \mathrm{~N}_{4} \mathrm{O}_{9}$ \\
\hline \multicolumn{3}{|l|}{ HRESI-MS (m/z) } \\
\hline \multirow{2}{*}{ Calculated } & 435.2086 & 449.2242 \\
\hline & $\left(\mathrm{C}_{17} \mathrm{H}_{30} \mathrm{~N}_{4} \mathrm{O}_{9}+\mathrm{H}\right)^{+}$ & $\left(\mathrm{C}_{18} \mathrm{H}_{32} \mathrm{~N}_{4} \mathrm{O}_{9}+\mathrm{H}\right)^{+}$ \\
\hline Found & $435.2089(\mathrm{M}+\mathrm{H})^{+}$ & $449.2243(\mathrm{M}+\mathrm{H})^{+}$ \\
\hline \multicolumn{3}{|l|}{ Color reaction } \\
\hline Positive & $\begin{array}{l}\mathrm{I}_{2} \text {, Rydon-Smith, iron(III) } \\
\text { chloride }\end{array}$ & $\begin{array}{l}\mathrm{I}_{2} \text {, Rydon-Smith, iron(III) } \\
\text { chloride }\end{array}$ \\
\hline Negative & Ninhydrin & Ninhydrin \\
\hline
\end{tabular}

A total of $600 \mathrm{~g}$ of the fermentation material was extracted with $\mathrm{EtOH}$ and was filtered. The filtrate containing the fradiamines was purified by column chromatography with CHP-20P eluted with $50 \% \mathrm{MeOH}$, and rechromatographed on the same column eluted with $0.01 \mathrm{~m} \mathrm{NaOH}$. Compounds 1 and 2 were separated during this process.

The fractions containing 1 were chromatographed on a CHP-20P column by stepwise-gradient elution from 0 to $60 \% \mathrm{MeOH}$. The fractions were further purified with reverse-phase octadecylsilane and HILIC (hydrophilic interaction liquid chromatography) HPLC to give $10.5 \mathrm{mg}$ of $\mathbf{1}$ as a colorless syrup.

The fractions containing 2 were further purified by CHP-20P column chromatography, eluted with $50 \% \mathrm{MeOH}$, loaded on a LH20 column and eluted with $50 \% \mathrm{MeOH}$ to give $187.3 \mathrm{mg}$ of 2 as a colorless syrup.

\section{Structure determination}

The physicochemical properties of the fradiamines are summarized in Table 1 . The UV spectra of $\mathbf{1}$ and $\mathbf{2}$ showed end absorption. Under the presence of molar equivalent of iron(III) chloride, characteristic absorbance was observed in visible range (Supplementary Figures S3 and S4). The IR spectra of 1 and 2 showed specific absorption derived from the amide bond $\left(\nu_{\max }\right.$ of 1 was 1637 and $1543 \mathrm{~cm}^{-1}$ and that of $\mathbf{2}$ was 1633 and $1542 \mathrm{~cm}^{-1}$ ). The color reaction of $\mathbf{1}$ and 2 on silica gel TLC were positive to the Rydon-Smith reaction and iron (III) chloride, and negative to ninhydrin. These data suggested that $\mathbf{1}$ and $\mathbf{2}$ were peptidic compounds. The molecular formulas of $\mathbf{1}$ and $\mathbf{2}$ were determined as $\mathrm{C}_{17} \mathrm{H}_{30} \mathrm{~N}_{4} \mathrm{O}_{9}$ and $\mathrm{C}_{18} \mathrm{H}_{32} \mathrm{~N}_{4} \mathrm{O}_{9}$, respectively, by LC-HRESI-MS. The ${ }^{1} \mathrm{H},{ }^{13} \mathrm{C}$ NMR and HMQC spectral data of the compounds are summarized in Table 2.

The ${ }^{13} \mathrm{C}$ NMR and DEPT135 spectra of 1 revealed the presence of two methyls, nine $s p^{3}$ methylenes, five carbonyls and an oxygenated $s p^{3}$ quaternary carbon. The presence of two amide protons in the ${ }^{1} \mathrm{H}$ NMR and four exchangeable protons were suggested by the molecular formula. The correlations from ${ }^{1} \mathrm{H}_{-}{ }^{1} \mathrm{H}$ COSY and HMBC are summarized in Figure 2a. The ${ }^{1} \mathrm{H}-{ }^{1} \mathrm{H}$ COSY spectrum revealed the connectivities from $\delta 8.02\left(1^{\prime}-\mathrm{NH}\right)$ to $\delta 3.47\left(4^{\prime}-\mathrm{H}\right)$ and from $\delta 7.76\left(1^{\prime \prime}-\mathrm{NH}\right)$ to $\delta 3.42$ and $3.49\left(5^{\prime \prime}-\mathrm{H}\right)$. These data suggested that 1 contained $\mathrm{C} 3$ and $\mathrm{C} 4$ alkyl diamine units. The HMBC spectrum revealed that $\mathbf{1}$ contains a citric acid core and two acetylated alkyl 
Table $2{ }^{1} \mathrm{H}$ and ${ }^{13} \mathrm{C}$ NMR data of 1 and 2 in DMSO- $d_{6}$

\begin{tabular}{|c|c|c|c|c|c|c|c|c|}
\hline \multirow[b]{2}{*}{ Position } & \multicolumn{4}{|c|}{1} & \multicolumn{4}{|c|}{2} \\
\hline & $\delta_{C}($ p.p.m.) & Multi ${ }^{a}$ & $\delta_{H}$ (p.p.m.) & Multi & $\delta_{C}($ p.p.m.) & Multi $^{\mathrm{a}}$ & $\delta_{H}$ (p.p.m.) & Multi \\
\hline 1 & 171.6 & $\mathrm{~s}$ & & & 171.3 & $\mathrm{~s}$ & & \\
\hline 2 & 43.1 & $\mathrm{t}$ & $2.41,2.60$ & d 14.6 , d 14.7 & 43.0 & $\mathrm{t}$ & $2.44,2.63$ & d 14.8 , d 14.8 \\
\hline 3 & 74.3 & $\mathrm{~s}$ & & & 74.3 & $\mathrm{~s}$ & & \\
\hline 4 & 42.4 & $\mathrm{t}$ & $2.44,2.50$ & $\mathrm{~m}, \mathrm{~m}$ & 42.2 & $\mathrm{t}$ & $2.46,2.51$ & d 14.3 , d 14.3 \\
\hline 5 & 170.5 & $\mathrm{~s}$ & & & 170.6 & $\mathrm{~s}$ & & \\
\hline 6 & 173.5 & $\mathrm{~s}$ & & & 173.3 & $\mathrm{~s}$ & & \\
\hline $1^{\prime}$ & & & 8.02 & $\mathrm{br}$ & & & 8.06 & brt 5.3 \\
\hline $2^{\prime}$ & 36.2 & $\mathrm{t}$ & 3.02 & $\mathrm{~m}$ & 36.2 & $\mathrm{t}$ & 3.02 & $\mathrm{~m}$ \\
\hline $3^{\prime}$ & 26.5 & $\mathrm{t}$ & 1.62 & $\mathrm{~m}$ & 26.5 & $\mathrm{t}$ & 1.62 & $\mathrm{~m}$ \\
\hline $4^{\prime}$ & 45.1 & $\mathrm{t}$ & 3.47 & $\mathrm{~m}$ & 45.1 & $\mathrm{t}$ & 3.47 & $\mathrm{~m}$ \\
\hline $5^{\prime}$ & & & 9.73 & brs & & & 9.73 & brs \\
\hline $6^{\prime}$ & 170.3 & $\mathrm{~s}$ & & & 170.3 & $\mathrm{~s}$ & & \\
\hline $7^{\prime}$ & 20.3 & $q$ & 1.96 & $\mathrm{~s}$ & 20.3 & $q$ & 1.95 & $\mathrm{~s}$ \\
\hline $1^{\prime \prime}$ & & & 7.76 & t 5.3 & & & 7.74 & t 5.8 \\
\hline $2^{\prime \prime}$ & 38.2 & $\mathrm{t}$ & 2.99, 3.07 & $\mathrm{~m}$ & 38.5 & $\mathrm{t}$ & 3.02 & $\mathrm{~m}$ \\
\hline $3^{\prime \prime}$ & 26.3 & $\mathrm{t}$ & 1.34 & $\mathrm{~m}$ & 28.7 & $\mathrm{t}$ & 1.38 & $\mathrm{~m}$ \\
\hline $4^{\prime \prime}$ & 23.6 & $\mathrm{t}$ & 1.47 & $\mathrm{~m}$ & 23.4 & $\mathrm{t}$ & 1.19 & $\mathrm{~m}$ \\
\hline $5^{\prime \prime}$ & 46.6 & $\mathrm{t}$ & $3.42,3.49$ & $\mathrm{~m}, \mathrm{~m}$ & 26.1 & $\mathrm{t}$ & 1.47 & $\mathrm{~m}$ \\
\hline $6^{\prime \prime}$ & & & 9.73 & brs & 46.8 & $\mathrm{t}$ & 3.44 & $\mathrm{~m}$ \\
\hline $7^{\prime \prime}$ & 170.1 & $\mathrm{~s}$ & & & & & 9.73 & brs \\
\hline $8^{\prime \prime}$ & 20.4 & $q$ & 1.96 & $\mathrm{~s}$ & 170.2 & $\mathrm{~s}$ & & \\
\hline $9^{\prime \prime}$ & & & & & 20.4 & $q$ & 1.95 & $\mathrm{~s}$ \\
\hline
\end{tabular}

aultiplicity and coupling constant in $\mathrm{Hz}$.

amines. The long-range couplings observed in the HMBC experiments can be summarized as follows. The cross-peaks from $\delta 2.41$ and $2.60(2-\mathrm{H})$ to $\delta 171.6(\mathrm{C}-1), \delta 74.3(\mathrm{C}-3), \delta 42.4(\mathrm{C}-4)$ and $\delta 173.5$ (C-6), and from $\delta 2.44$ and $2.50(4-\mathrm{H})$ to $\delta 43.1(\mathrm{C}-2), \delta 74.3(\mathrm{C}-3)$, $\delta 170.5$ (C-5) and $\delta 173.5$ (C-6) supported the presence of citric acid. The cross-peak from $\delta 1.96\left(7^{\prime}-\mathrm{H}\right)$ to $\delta 170.3\left(\mathrm{C}-6^{\prime}\right)$ and $\delta 1.96\left(8^{\prime \prime}-\mathrm{H}\right)$ to $\delta 170.1\left(\mathrm{C}-7^{\prime \prime}\right)$ supported the presence of two acetyl groups. The nitrogen-bearing methylene at $\delta 3.47\left(4^{\prime}-\mathrm{H}\right)$ showed a correlation with the carbonyl carbon at $\delta 170.3\left(\mathrm{C}-6^{\prime}\right)$, thus establishing the connectivity of the $\mathrm{C} 3$ alkyl diamine to the $\mathrm{N}$-acetyl group. The alkyl proton at $\delta 3.42$ and $3.49\left(5^{\prime \prime}-\mathrm{H}\right)$ showed a correlation with the carbonyl carbon at $\delta 170.1\left(\mathrm{C}-7^{\prime \prime}\right)$, establishing the connectivity of the $\mathrm{C} 4$ alkyl diamine to another $\mathrm{N}$-acetyl group in the same manner. The amide proton at $\delta 8.02\left(1^{\prime}-\mathrm{H}\right)$ showed a correlation with the carbonyl carbon at $\delta 170.5$ (C-5); thus, the C3 alkyl amine and the carbonyl carbon (C-5) formed a peptide bond. The amide proton at $\delta 7.76\left(1^{\prime \prime}-\mathrm{H}\right)$ showed a correlation with the carbonyl carbon at $\delta 173.5$ (C-6), establishing the connectivity of the $\mathrm{C} 4$ alkyl amine to the C-6 carbonyl carbon via a peptide bond. The remaining atoms were estimated to be hydroxyl groups connected with C-1, C-3, N-5' and $\mathrm{N}-6$ " to form a carboxylic acid $\mathrm{OH}$, a tertiary $\mathrm{OH}$ and two $\mathrm{N}$-hydroxy groups, respectively, from the molecular formula of 1 . The MS/MS fragments $(\mathrm{m} / \mathrm{z} 147.1128$ and $\mathrm{m} / \mathrm{z} 133.0970)$ of $\mathbf{1}$ and downfield shifts of the $N$-hydroxy groups bearing a methylene at C- $4^{\prime}$ and C-5" compared with the amide $\mathrm{NH}$ bearing a methylene at C-2' and C-2" and positive color reaction with iron(III) chloride on TLC supported the position of the $\mathrm{N}$-hydroxy groups (Figure 2c). The planar structure of $\mathbf{1}$ was determined as shown in Figure 1a.

The NMR data of $\mathbf{2}$ were very similar to that of $\mathbf{1}$. The presence of a longer methylene chain was suggested by the ${ }^{1} \mathrm{H}-{ }^{1} \mathrm{H}$ COSY and the HMBC revealed a longer methylene chain connected from $\delta 7.74\left(1^{\prime \prime}-\mathrm{NH}\right)$ to $\delta 3.44\left(6^{\prime \prime}-\mathrm{H}\right)$ (Figure $\left.2 \mathrm{~b}\right)$. Moreover, the observed fragment ion at $m / z 161.1285$ instead of $m / z 147.1128$ from MS/MS analysis (Figure 2d) also supported the presence of the longer methylene chain. Based on these results and the molecular formula, the planar structure of $\mathbf{2}$ was determined as shown in Figure $1 \mathrm{~b}$.

The compounds contained a carboxylic acid and two $N$-hydroxyl groups, features of iron chelators. Thus, we determined that both compounds were siderophores. Compound 1 was new and 2 was patented as a sweetness enhancer. ${ }^{16}$ These compounds had two alkyl diamines asymmetrically bonded to the citric acid core. A related structure, aerobactin, known as a bacterial siderophore, was isolated from Aerobacter aerogenes, ${ }^{17}$ rhizobactin 1021 was isolated from Rhizobium meliloti ${ }^{18}$ and schizokinen was isolated from Bacillus megaterium. ${ }^{19}$ However, almost no similar structures were identified from actinomycetes. Moreover, structures containing asymmetrically bonded alkyl diamines with a citric acid core are very rare in siderophores including bacterial siderophores. LC-HRESI-MS analysis is a suitable method for screening secondary metabolites of actinomycetes for new compounds with unique structures.

\section{Antimicrobial activity}

It is known that some siderophores have moderate antibiotic activities against some bacteria, such as nocardamine isolated from Nocardia $\mathrm{sp}^{20}$ and madurastatins isolated from Actinomadura madurae. ${ }^{21}$ Thus, the antimicrobial activity of $\mathbf{1}$ and $\mathbf{2}$ was evaluated along with other synthetic or natural siderophores against Gram-positive and Gram-negative bacteria including anaerobic bacteria. The antimicrobial activities of the compounds are shown in Table 3 . Compounds $\mathbf{1}$ and $\mathbf{2}$ exhibited moderate antimicrobial activities against Clostridium difficile BAA-1382 at 32 and $8 \mu \mathrm{g} \mathrm{ml}^{-1}$, respectively. The antimicrobial activities of the compounds were, however, cancelled dose-dependently under the presence of iron(III) chloride (Supplementary Table S1). The spectra of antimicrobial activities of 
a

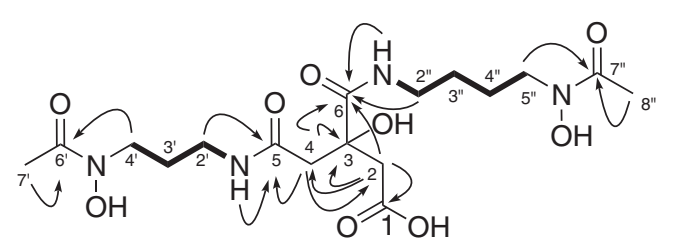

C

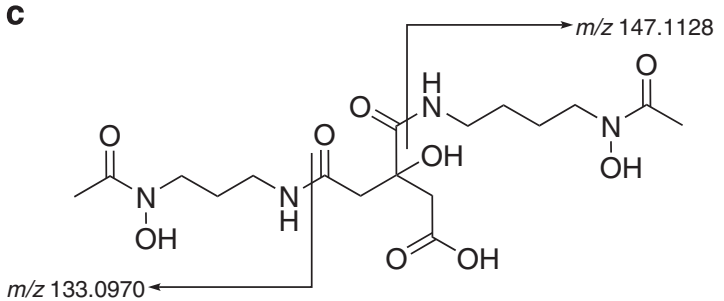

b

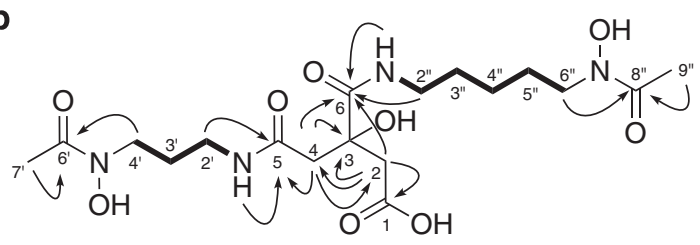

$-{ }^{1} \mathrm{H}-{ }^{1} \mathrm{H}$ COSY

$\mathrm{HMBC}$

d

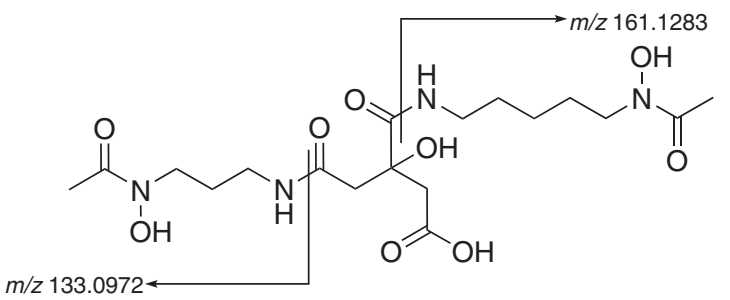

Figure 2 Key COSY (bold lines) and HMBC (single-headed arrows) correlations for compounds $\mathbf{1}$ (a) and 2 (b). MS/MS analyses of 1 (c) and 2 (d).

Table 3 Antimicrobial activities of 1 and 2

\begin{tabular}{|c|c|c|c|c|c|c|}
\hline \multirow[b]{2}{*}{ Test microorganisms } & & \multicolumn{5}{|c|}{$M I C\left(\mu g m l^{-1}\right)$} \\
\hline & & 1 & 2 & Tiron & Nocardamine & Mycobactin J \\
\hline C. butyricum & JCM 1391T & 64 & 128 & 32 & 16 & 16 \\
\hline C. difficile & BAA-1382 & 32 & 8 & 16 & 8 & 32 \\
\hline C. indolis & JCM 1380T & $>128$ & 16 & 32 & 16 & $>64$ \\
\hline C. perfringens & B-0866 & $>128$ & $>128$ & $>128$ & 32 & $>128$ \\
\hline C. ramosum & JCM 1298T & $>128$ & 64 & 64 & 32 & $>64$ \\
\hline
\end{tabular}

the compounds were similar to those of other siderophores (Supplementary Tables S2 and S3).

\section{METHODS}

\section{General}

The optical rotations of the purified compounds were measured using a P-1030 polarimeter (JASCO, Tokyo, Japan). The UV spectra were recorded with a U-2800 UV-Vis spectrophotometer (Hitachi High-Technologies, Tokyo, Japan). The IR spectra were recorded with an FT/IR-4100 Fourier transform infrared spectrometer (JASCO). The ${ }^{1} \mathrm{H}$ and ${ }^{13} \mathrm{C}$ NMR spectra were measured with an AVANCE III 500 spectrometer (Bruker, Billerica, MA, USA) and an ECZ600R spectrometer (JEOL RESONANCE, Tokyo, Japan) at $25^{\circ} \mathrm{C}$ using tetramethylsilane as an internal reference. The mass spectra were recorded using a Q Exactive or LTQ Orbitrap XL mass spectrometer (Thermo Fisher Scientific, San Jose, CA, USA).

\section{Screening}

A total of 239 deep-sea actinomycetes were extracted with EtOH. The 10-fold diluted EtOH extract was analyzed with LC-HRESI-MS. HPLC was performed using a SPELCO Ascentis Express $\mathrm{C}_{18}$ column $(2.1 \mathrm{~mm}$ i.d. $\times 50 \mathrm{~mm}$; Sigma-Aldrich, St Louis, MO, USA) at $40^{\circ} \mathrm{C}$. The mobile phase consisted of $0.1 \% \mathrm{HCOOH}$ aq. (A) and $0.1 \% \mathrm{HCOOH}-\mathrm{CH}_{3} \mathrm{CN}(\mathrm{B})$, with a gradient of $95 \% \mathrm{~A}$ to $0 \% \mathrm{~A}(0-5 \mathrm{~min}), 0 \% \mathrm{~A}(5-8.5 \mathrm{~min})$ and $95 \% \mathrm{~A}(8.5-12 \mathrm{~min})$. The flow rate was $0.4 \mathrm{ml} \mathrm{min}^{-1}$. Compound 1 and 2 was eluted at 1.32 and
$1.60 \mathrm{~min}$, respectively. MS data acquisition was performed sequentially in the order of positive full MS, negative full MS and positive MS/MS using a heated ESI probe with a spray voltage of $4 \mathrm{kV}$, a capillary temperature of $350{ }^{\circ} \mathrm{C}$ and an S lens RF level of 50. The MS range was scanned from $\mathrm{m} / \mathrm{z} 133.5$ to 2000 (full MS resolution 35000 and MS/MS resolution 17500 ). The MS data analyses were performed by Xcalibur 2.2 (Thermo Fisher Scientific) and the component extraction software SIEVE 2.2 was used (Thermo Fisher Scientific) to get accurate masses and the retention time index.

\section{Taxonomic studies of the strain MM456M-mF7}

Morphological properties were observed following incubation at $30^{\circ} \mathrm{C}$ for 21 days on yeast extract-malt agar (ISP medium no. 2), oatmeal agar (ISP medium no. 3) and inorganic salt-starch agar (ISP medium no. 4). Detailed observation of mycelial morphology was performed using a scanning electron microscope (SU-1510; Hitachi High-Technologies) after the strain MM456M-mF7 was incubated on ISP medium no. 4 at $30{ }^{\circ} \mathrm{C}$ for 7 days. The type of diaminopimelic acid isomers in the whole-cell hydrolysates was determined by the method of Staneck and Roberts. ${ }^{22}$ The total DNA of MM456M-mF7 was prepared using a Genomic DNA Extraction Kit Mini (RBC Bioscience, New Taipei, Taiwan) according to the manufacturer's instructions. 16S rRNA (positions 56-1495, Escherichia coli numbering system $^{23}$ ) was amplified by PCR and sequenced. A search for the most closely related sequences was performed using the BLAST algorithm at the DNA Data Bank of Japan. 


\section{Fermentation}

A slant culture of MM456M-mF7 was inoculated into a $500 \mathrm{ml}$ baffled Erlenmeyer flask containing $110 \mathrm{ml}$ of seed medium consisting of $2 \%\left(\mathrm{w} \mathrm{v}^{-1}\right)$ galactose, $2 \%\left(\mathrm{w} \mathrm{v}^{-1}\right)$ dextrin, $1 \%\left(\mathrm{w} \mathrm{v}^{-1}\right)$ Bacto-soytone (Becton, Dickinson and Company, Franklin Lakes, NJ, USA), $0.5 \%\left(\mathrm{w} \mathrm{v}^{-1}\right)$ corn steep liquor (Kogo Starch, Chiba, Japan), $1 \%\left(\mathrm{w} \mathrm{v} \mathrm{v}^{-1}\right)$ glycerol, $0.2 \%\left(\mathrm{w} \mathrm{v}^{-1}\right)\left(\mathrm{NH}_{4}\right)_{2} \mathrm{SO}_{4}$, $0.2 \%\left(\mathrm{w} \mathrm{v}^{-1}\right) \mathrm{CaCO}_{3}$ and $1.8 \%\left(\mathrm{w} \mathrm{v}^{-1}\right)$ artificial seawater (Nihon Pharmaceutical, Tokyo, Japan) in deionized water ( $\mathrm{pH} 7.4$ before sterilization). The seed culture was incubated in a rotary shaker $\left(180\right.$ r.p.m.) at $27^{\circ} \mathrm{C}$ for 2 days. The producing culture was performed by solid-state fermentation. A total of $7 \mathrm{ml}$ of seed culture was transferred into a $500 \mathrm{ml} \mathrm{K}-1$ flask containing $40 \mathrm{~g}$ of a producing medium consisting of pressed barley $(15 \mathrm{~g})$ and deionized water ( $25 \mathrm{~g}$ ). The fermentation was carried out at $30^{\circ} \mathrm{C}$ for 14 days in the dark.

\section{Isolation}

Purification was guided by obtaining accurate masses using LC-HRESI-MS analysis. The whole fermentation material $(600 \mathrm{~g})$ was extracted two times with an equal amount of EtOH and the extract was passed through filter paper. The filtrate was diluted 10 -fold with deionized water and adjusted to $\mathrm{pH} 2.0$ with $\mathrm{HCl}$. The diluted filtrate was applied to a Diaion CHP-20P column (500 ml; Mitsubishi Chemical, Tokyo, Japan). After washing with water, the compounds were eluted with $50 \% \mathrm{MeOH}$. The eluate was concentrated and dissolved in $\mathrm{MeOH}$ to remove insoluble contaminants. The $\mathrm{MeOH}$ supernatant was concentrated in vacuo to give $4.4 \mathrm{~g}$ of crude material. The material was adjusted to $\mathrm{pH} 2.0$ and chromatographed on a CHP-20P column $(200 \mathrm{ml})$, eluted with $0.01 \mathrm{M} \mathrm{NaOH}$, and the fractions of interest were neutralized with $\mathrm{HCl}$. At this stage, 1 and 2 were almost separated. The $\mathrm{NaOH}$ fractions primarily containing 1 ( $496.3 \mathrm{mg}$ ) were adjusted to $\mathrm{pH} 2.0$ and then loaded on a CHP-20P column $(110 \mathrm{ml})$, and eluted using a stepwise gradient of $0-60 \%$ $\mathrm{MeOH}$ (10\% increment). Compound 1 was eluted from 20 to $40 \% \mathrm{MeOH}$ $(77.1 \mathrm{mg})$. The fractions of interest were further purified using a preparative HPLC column (Capcell Pak C ${ }_{18}$ MG, $20 \mathrm{~mm}$ i.d. $\times 250 \mathrm{~mm}$; Shiseido, Tokyo, Japan), eluted with $8 \%$ aqueous acetonitrile at a flow rate of $10 \mathrm{ml} \mathrm{min}^{-1}$. Compound 1 was eluted from 23 to $27 \mathrm{~min}$. Finally, the combined fractions were purified using a preparative HILIC HPLC column (PC HILIC, $20 \mathrm{~mm}$ i.d. $\times 250 \mathrm{~mm}$; Shiseido), with linear-gradient elution from 95 to $50 \%$ aqueous acetonitrile over $45 \mathrm{~min}$ at a flow rate of $10 \mathrm{ml} \mathrm{min}^{-1}$. Purified 1 was eluted from 22 to $24 \mathrm{~min}$ to give a colorless syrup $(10.5 \mathrm{mg})$. The $\mathrm{NaOH}$ fractions primarily containing $2(687.2 \mathrm{mg})$ were adjusted to $\mathrm{pH} 2.0$ and were then applied to a CHP-20 P column $(110 \mathrm{ml})$. After washing with water, 2 was eluted with $50 \% \mathrm{MeOH}$. The eluate $(451.4 \mathrm{mg})$ was chromatographed on a Sephadex LH-20 column (50 ml; GE Healthcare Bio-Science AB, Uppsala, Sweden), eluted isocratic with $50 \% \mathrm{MeOH}$. The selected fractions were concentrated in vacuo to give 2 as a colorless syrup (187.3 mg).

\section{Antimicrobial activity of the compounds}

Clostridium perfringens B-0866 was from the in-house collection of the Institute of Microbial Chemistry. C. difficile BAA-1382 was purchased from the American Type Culture Collection (Manassas, VA, USA). Other microbial strains were purchased from the Japan Collection of Microorganisms (Tsukuba, Japan). MICs were determined by the standard agar dilution method recommended by the Clinical and Laboratory Standards Institute guidelines. ${ }^{24}$ Bacteria were incubated on ABCM agar (Eiken Chemical, Tokyo, Japan) at $37^{\circ} \mathrm{C}$ under anaerobic culture conditions for $20 \mathrm{~h}$. Moreover, MICs were also determined by the microbroth dilution method under the presence of the iron (III) chloride hexahydrate (Wako Pure Chemical Industries, Osaka, Japan) to confirm that the antimicrobial activities were attributed to chelating activity (Supplementary Table S1).

\section{CONFLICT OF INTEREST}

The authors declare no conflict of interest.

\section{ACKNOWLEDGEMENTS}

This study was supported by the Japan Society for the Promotion of Science (26450107). We thank Y Kubota, C Hayashi and Y Shibuya for providing technical assistance.

1 Newman, D. J. \& Cragg, G. M. Natural products as sources of new drugs over the 30 years from 1981 to 2010. J. Nat. Prod. 75, 311-335 (2012).

2 Bérdy, J. Bioactive microbial metabolites. J. Antibiot. 58, 1-26 (2005).

3 Bérdy, J. Thoughts and facts about antibiotics: where we are now and where we are heading. J. Antibiot. 65, 385-395 (2012).

4 Demain, A. L. \& Sanchez, S. Microbial drug discovery: 80 years of progress. J. Antibiot. 62, 5-16 (2009).

5 Flärdh, K. \& Buttner, M. J. Streptomyces morphogenetics: dissecting differentiation in a filamentous bacterium. Nat. Rev. Microbiol. 7, 36-49 (2009).

6 Scherlach, K. \& Hertweck, C. Triggering cryptic natural product biosynthesis in microorganisms. Org. Biomol. Chem. 7, 1753-1760 (2009).

7 Mayer, A. M. S., Rodríguez, A. D., Taglialatela-Scafati, O. \& Fusetani, N. Marine pharmacology in 2009-2011: marine compounds with antibacterial, antidiabetic, antifungal, anti-inflammatory, antiprotozoal, antituberculosis, and antiviral activities; affecting the immune and nervous systems, and other miscellaneous mechanisms of action. Mar. Drugs 11, 2510-2573 (2013).

8 Feling, R. H. et al. Salinosporamide A: a highly cytotoxic proteasome inhibitor from a novel microbial source, a marine bacterium of the new genus Salinospora. Angew. Chem. Int. Ed. Engl. 42, 355-357 (2003).

9 Romero, F. et al. Thiocoraline, a new depsipeptide with antitumor activity produced by a marine Micromonospora. I. Taxonomy, fermentation, isolation, and biological activities. J. Antibiot. 50, 734-737 (1997)

10 Umezawa, S., Tsuchiya, T., Tatsuta, K., Horiuchi, Y. \& Usui, T. A new antibiotic, dienomycin. I. Screening method, isolation and chemical studies. J. Antibiot. 23 20-27 (1970)

11 Omura, S. et al. A new alkaloid AM-2282 of Streptomyces origin. Taxonomy, fermentation, isolation and preliminary characterization. J. Antibiot. 30 275-282 (1977).

12 Nakashima, T. et al. Trehangelins A, B and C, novel photo-oxidative hemolysis inhibitors produced by an endophytic actinomycete, Polymorphospora rubra K07-0510. J. Antibiot. 66, 311-317 (2013).

13 Nakashima, T. et al. Mangromicins A and B: structure and antitrypanosomal activity of two new cyclopentadecane compounds from Lechevalieria aerocolonigenes K10-0216. J. Antibiot. 67, 253-260 (2014).

14 Nakashima, T., Kamiya, Y., Iwatsuki, M., Takahashi, Y. \& Omura, S. Mangromicins, six new anti-oxidative agents isolated from a culture broth of the actinomycete, Lechevalieria aerocolonigenes K10-0216. J. Antibiot. 67, 533-539 (2014).

15 Nakashima, T. et al. Mangromicin C, a new analog of mangromicin. J. Antibiot. 68 220-222 (2015).

16 Krohn, M. et al. Sweetness enhancers, sweetener compositions, methods of making the same and consumables containing the same. Patent WO2012107201A2 (2012).

17 Gibson, F. \& Magrath, D. I. The isolation and characterization of a hydroxamic acid (aerobactin) formed by Aerobactar aerogenes 62-I. Biochim. Biophys. Acta 192 , 175-184 (1969).

18 Persmark, M. et al. Isolation and structure of rhizobactin 1021, a siderophore from the alfalfa symbiont Rhizobium meliloti 1021. J. Am. Chem. Soc. 115, 3950-3956 (1993).

19 Mullis, K. B., Pollack, J. R. \& Neilands, J. B. Structure of schizokinen, an iron-transport compound from Bacillus megaterium. Biochemistry 10, 4894-4898 (1971).

20 Stoll, A., Brack, A. \& Renz, J. Nocardamin, ein neues antibioticum aus einer NocardiaArt. Schweiz Pathol. Bacteriol. 14, 225-233 (1951).

21 Harada, K. et al. Isolation and structural characterization of siderophores, madurastatins, produced by a pathogenic Actinomadura madurae. J. Antibiot. 57, 125-135 (2004).

22 Staneck, J. L. \& Roberts, G. D. Simplified approach to identification of aerobic actinomycetes by thin-layer chromatography. Appl. Microbiol. 28, 226-231 (1974).

23 Brosius, J., Palmer, M. L., Kennedy, P. J. \& Noller, H. F. Complete nucleotide sequence of a 16 S ribosomal RNA gene from Escherichia coli. Proc. Natl Acad. Sci. USA 75, 4801-4805 (1978).

24 Clinical and Laboratory Standards Institute. Methods for Antimicrobial Susceptibility Testing of Anaerobic Bacteria; Approved Standard-Eighth Edition, (CLSI, Wayne, NJ, USA, 2012).

Supplementary Information accompanies the paper on The Journal of Antibiotics website (http://www.nature.com/ja) 